\title{
Transcriptomic analysis reveals specific osmoregulatory adaptive responses in gill mitochondria-rich cells and pavement cells of the Japanese eel
}

Keng Po Lai ${ }^{1+}$, Jing-Woei $\mathrm{Li}^{2,3+}$, Je Gu${ }^{4}$, Ting-Fung Chan², William Ka Fai Tse ${ }^{4 *}$ and Chris Kong Chu Wong ${ }^{4, *^{*}}$

\begin{abstract}
Background: Homeostasis of ions and water is important for the maintenance of cellular functions. The regulation of the homeostasis is particularly important in euryhaline fish that migrate between freshwater (FW) and seawater (SW) environments. The fish gill, the major tissue that forms an interface separating the extracellular fluids and external water environment, has an effective transport system to maintain and regulate a constant body osmolality. In fish gills, the two major epithelial cells, pavement cells (PVCs) and mitochondria-rich cells (MRCs), are known to play key and complementary roles in ion transport at the interface. Discovering the robust mechanisms underlying the two cell types' response to osmotic stress would benefit our understanding of the fundamental mechanism allowing PVCs and MRCs to handle osmotic stress. Owing to the limited genomic data available on estuarine species, existing knowledge in this area is slim. In this study, transcriptome analyses were conducted using PVCs and MRCs isolated from Japanese eels adapted to FW or SW environments to provide a genome-wide molecular study to unravel the fundamental processes at work.
\end{abstract}

Results: The study identified more than 12,000 transcripts in the gill cells. Interestingly, remarkable differential expressed genes (DEGs) were identified in PVCs (970 transcripts) instead of MRCs (400 transcripts) in gills of fish adapted to FW or SW. Since PVCs cover more than $90 \%$ of the gill epithelial surface, the greater change in gene expression patterns in PVCs in response to external osmolality is anticipated. In the integrity pathway analysis, 19 common biological functions were identified in PVCs and MRCs. In the enriched signaling pathways analysis, most pathways differed between PVCs and MRCs; 14 enriched pathways were identified in PVCs and 12 in MRCs. The results suggest that the osmoregulatory responses in PVCs and MRCs are cell-type specific, which supports the complementary functions of the cells in osmoregulation.

Conclusions: This is the first study to provide transcriptomic analysis of PVCs and MRCs in gills of eels adapted to FW or SW environments. It describes the cell-type specific transcriptomic network in different tonicity. The findings consolidate the known osmoregulatory pathways and provide molecular insight in osmoregulation. The presented data will be useful for researchers to select their targets for further studies.

Keywords: Next generation sequencing, Osmotic stress, Fish

\footnotetext{
* Correspondence: kftse@hkbu.edu.hk; ckcwong@hkbu.edu.hk

${ }^{\dagger}$ Equal contributors

${ }^{4}$ Department of Biology, Hong Kong Baptist University, Kowloon Tong, Hong

Kong

Full list of author information is available at the end of the article
} 


\section{Background}

Ion-osmoregulation is vital for the maintenance of tissue and cellular functions. It is important not only to define intracellular osmolality and cell shape, but it is also crucial for guiding many cellular functions, including transepithelial transport, cellular metabolism, and cell migration [1]. The fundamental mechanism of the regulation is highly conserved in metazoan; however, plasticity and efficiency of the regulation may vary with respect to the evolutionary development of animals during adaptation. Aquatic organisms are known to have well-developed osmoregulatory apparatus to regulate fluid and ion transport when faced with changes in water osmolality and to maintain a constant body osmolality. In euryhaline fish (i.e., salmon and eels), those that are naturally exposed to waters of varying salinity during their life cycles, maintaining a constant plasma osmolality when faced with an osmotic challenge has become a habitual and normal process. The gills of euryhaline fish are recognized as highly efficient ionosmoregulatory apparatus evolved to adapt to large changes in external osmolality. Therefore, it is an excellent tissue model to reveal the fundamental mechanism associated with plasticity in ion-osmoregulatory processes.

There are two major types of gill cells, the pavement cells (PVCs) and the mitochondria-rich cells (MRCs), which play key roles in ion-osmoregulation, namely sodium $\left(\mathrm{Na}^{+}\right)$, chloride $\left(\mathrm{Cl}^{-}\right)$, and calcium $\left(\mathrm{Ca}^{2+}\right)$ transport, and acid-base balance. Early studies using electron microscopic analysis reported remodeling of gill tissues and identified changes in the relative abundance of PVCs and MRCs in fish acclimated to waters of different salinities $[2,3]$. Electrophysiological studies using an alternate inner opercular membrane tissue model have indirectly demonstrated the ion transport functions of gill cells $[4,5]$. Later studies, using both histochemical and nucleic acid analyses, showed the spatiotemporal expression of different ion transporters in PVCs and MRCs of fish acclimated to freshwater (FW) or seawater (SW) environments, with the aim of delineating possible functions $[6,7]$. The techniques of subtractive hybridization, microarray, and rapid amplification of cDNA ends (RACEs) have been applied to reveal differential gene expressions in gill tissues collected from FW- or SW-adapted fish [8-10]. However, the significance of the studies was hindered by the limitation in identifying new transcripts with low sequence similarities to the existing sequence databases. Nonetheless, different working models to describe the ion transport activities of the two cell types have been proposed and described in recent review papers $[1,11]$. Basically, the growth and differentiation of gill PVCs and MRCs were found to respond differently in FW and SW environments and the cells played different but complementary roles in ion transport [12-14]. Findings during the past decades have provided unequivocal evidence strengthening our understanding of the fundamental mechanism of the cells in ion-osmoregulation; however, the scope of the studies has largely been limited by the availability of molecular tools (i.e., genomic database, homogeneous antibody) in the fish species. Therefore, advancement of the understanding of the fundamental molecular mechanisms undertaken in the two cell types has been challenging. Knowledge gaps in differential responses of PVCs and MRCs to osmotic stress have been identified. In this study, we hypothesized that PVCs and MRCs adopt different molecular mechanisms against an osmotic challenge to gain functional plasticity with respect to their roles and anatomical localizations. We aimed to conduct transcriptomic analysis of isolated PVCs and MRCs from both FW- and SW-adapted eels, followed by bioinformatics analysis and data verification, to decipher the molecular processes undertaken in these two type of cells.

\section{Results and Discussion}

Ion-osmoregulation is one of the key physiological processes essential for the maintenance of a consistent internal environment. Euryhaline fish are known to be an important model in the investigation of this fundamental and evolutionarily conserved process. In 2012, the first draft genome sequence of the Japanese eel was reported, in which a total assembled genome size was $1.15 \mathrm{Gbp}$ and an N50 of 52,849 bp was produced using the Illumina platform [15]. Moreover, transcriptomic analysis of juvenile European eels or specific body tissues (i.e., gills and corpuscles of the Stannius gland) of Japanese eels were published using the Roche 454 or Illumina MiSeq platform [16-18]. In the gill transcriptome of the Japanese eel, 11,033 transcripts were identified in fish adapted to FW or SW conditions [17]. In a recent study using tilapia (Oreochromis mossambicus) as the model fish with the 454 platform, more than 5,000 annotated gill transcripts were reported [19]. The transcriptomic analysis of fish gills summarized differential expressed genes in both hypo- and hyper-osmoregulation. However, the molecular responses in the gill PVCs and MRCs in relation to their functional phenotypes are still unknown.

In this study, we conducted transcriptomic analysis to identify differential gene expression profiles in gill PVCs and MRCs from Japanese eels adapted to FW or SW conditions. To move beyond previous transcriptomic analyses of fish gills, we used our established gill cell isolation protocol, a discontinuous Percoll gradient centrifugation, to enrich the two cell types, with cell purity greater than $85 \%[20,21]$. The method was validated by other research groups and applied for functional characterization of the individual cell types in other fish models [22, 23]. Furthermore, flow cytometry and electronic microscopy characterizing the two types of cells 
had been performed in our group to confirm the fraction specificity $[24,25]$. After RNA sequencing of the isolated cell types, we profiled and compared the expression levels of transcripts derived from the four groups of samples, (i) FW PVCs, (ii) SW PVCs, (iii) FW MRCs, and (iv) SW MRCs, using the Database for Annotation, Visualization, and Integrated Discovery (DAVID) and Ingenuity Pathway Analysis (IPA) bioinformatics analysis. The general workflow is shown in Fig. 1. The results, presented here for the first time, demonstrated the genome-wide molecular regulatory networks undertaken in gill PVCs and MRCs in response to osmotic challenges.

\section{The transcriptome of gill PVCs and MRCs generated by the Mi-Seq platform}

Sequencing libraries were prepared by enriched populations of PVCs and MRCs in both FW and SW conditions. Using the Illumina MiSeq platform, 9.5 M reads per sample, with a total of $11.1 \mathrm{~Gb}$ throughput, were obtained. Among 233,273 assembled contigs, a total of 12,003 transcripts were identified in reference to the UniProtKB/Swiss-Prot database (Fig. 1; Additional file 1). The distribution of contig-length ranged from 200 to $16,333 \mathrm{bp}$ and the average contig-length was $783 \mathrm{bp}$. The N75, N50, and N25 were $0.7 \mathrm{~kb}, 1.3 \mathrm{~kb}$, and $2.5 \mathrm{~kb}$, respectively
(Fig. 2a). Regarding the taxonomic distribution of the identified 12,003 genes, $25.9 \%$ of the genes showed the highest similarities to Lepisosteus oculatus, followed by Oncorhynchus mykiss (19.6 \%) and Danio rerio (10.9 \%) (Fig. 2b; Additional file 2). The low percentage of the matched genes from Anguilla species ( $0.3 \%$ in this study) is due to the lack of qualified genome databases and limited protein sequences of the fish species deposited in the UniProt database [18].

In comparing the cell-type specific (PVCs v. MRCs) transcriptome data with our previous published wholegill transcriptome [17], 7,034 transcripts were found to be commonly annotated (Additional file 3 ). Nine hundred eighty-three newly annotated transcripts were first identified in this study. We matched our data to the National Center for Biotechnology Information (NCBI) database, in which 259 Anguilla japonica transcripts with complete coding sequences were available. In BLASTN, we found that $161(62 \%)$ deposited sequences matched our unified PVC/MRC transcript data. Among those, 125 of 161 sequences showed excellent hits with E-values equal to zero, while another 27 sequences had E-values less than 1E-50 (Fig. 3a). The coverage of the sequence lengths is shown in Fig. 3b. The data showed that the majority of the assembled sequences exhibited excellent hits $(\mathrm{E}$-value $=0$ ), and most of them were covered by at least $75 \%$ mRNA

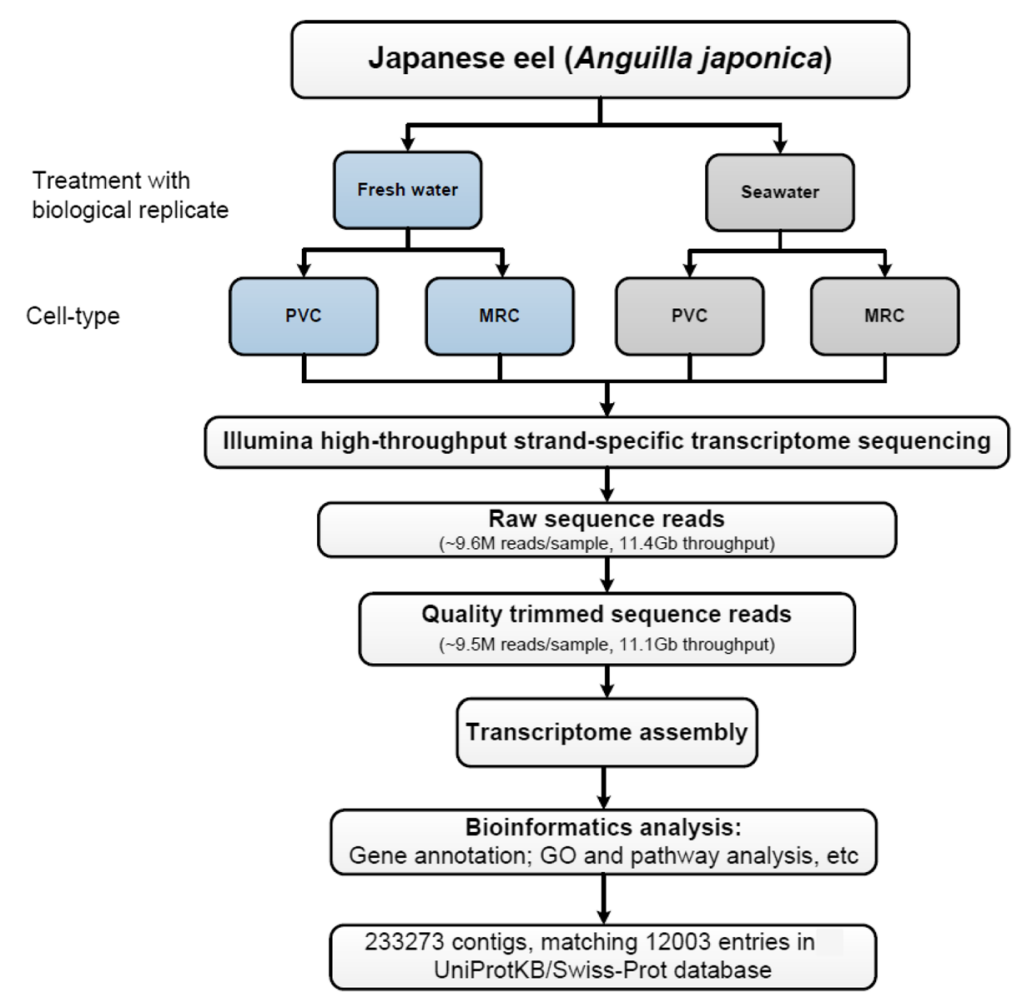

Fig. 1 Workflow of Illumina deep sequencing and bioinformatics analyses. It includes sample preparation, cDNA library construction, Illumina sequencing, and data analyses including transcriptome assembly, BLAST search, GO annotation, IPA analysis, and gene expression analysis 

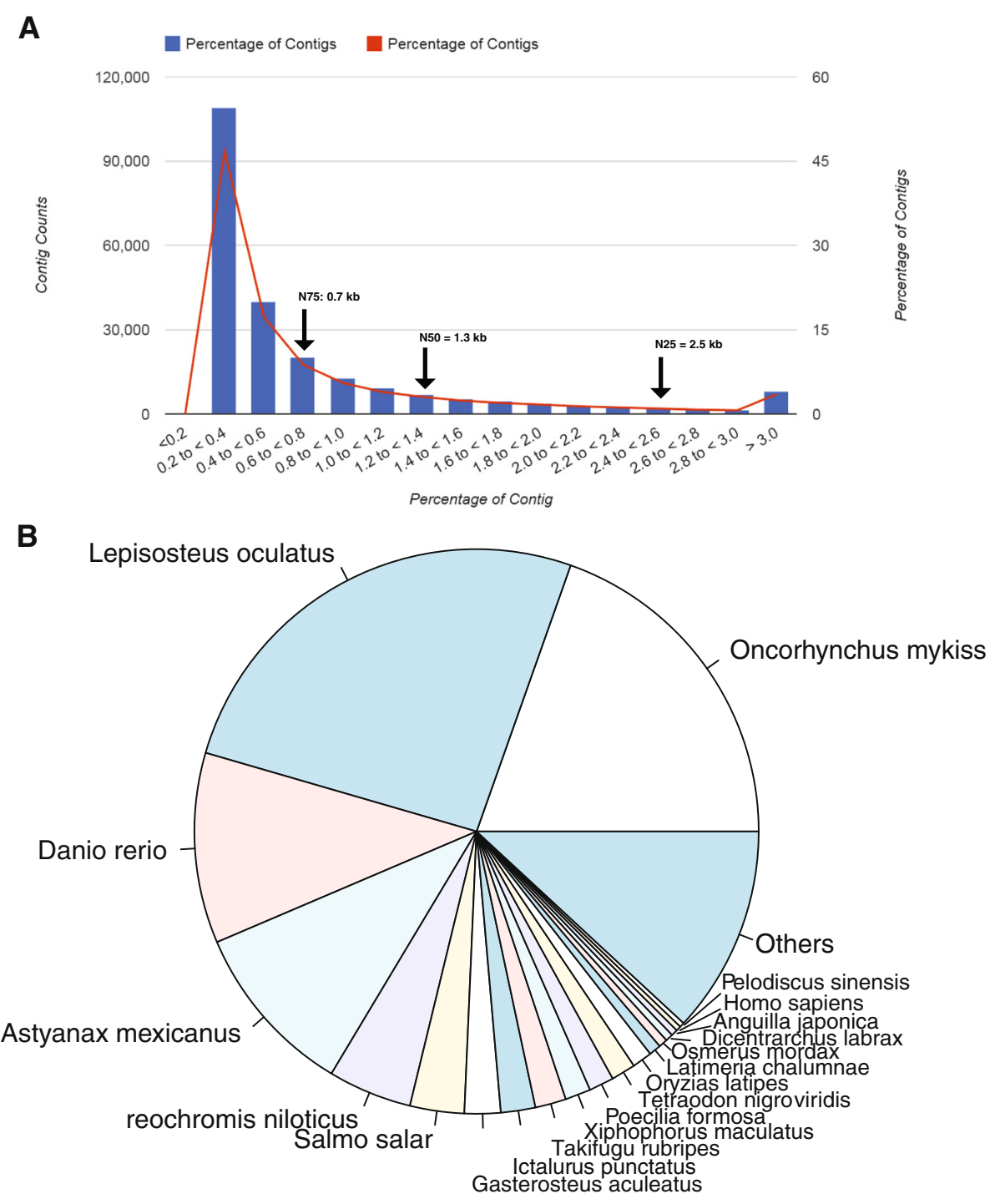

Fig. 2 Summary of the de novo assembly of the eel gill PVCs and MRCs transcriptome. a Distribution of the assembled contigs with different contig length (kb). Included are contig lengths for N-25, N-50, and N-75. b Species distribution of matched genes, with the highest similarity to Lepisosteus oculatus

sequence with respect to the full-length transcript deposited in the NCBI database.

In Fig. 4, a Venn diagram shows the relations among the four PVC and MRC datasets. In PVCs, there were 10,392 transcripts expressed in both FW and SW conditions. While in MRCs, 9,811 transcripts were commonly expressed in both conditions. Three differential expressed genes, two isoforms of carbonic anhydrase (CA: cah4 and cah7) and one chloride channel (clcn2) commonly expressed in both PVCs and MRCs were chosen for validation. The results of the quantitative polymerase chain reaction (PCR) analysis supported the transcriptome data in which FW PVCs and FW MRCs showed greater expression levels of $\operatorname{clcn} 2$ and cah7, but lower expression levels of cah4 compared to the corresponding SW samples (Fig. 5). CLCN2, a chloride channel, belongs to the CLC family of chloride channel/transport proteins. In humans, CLCN2 has been suggested to function in the chloride efflux pathway [26] and its mutation is linked to a central nervous system disorder [27]. While in zebrafish, clcn 2 is suggested to take part in chloride uptake with the apical sodium chloride cotransporter $2 \mathrm{~b}$ expressing cells, and highly expressed in the MRCs $[28,29]$. The greater expression of clcn2 in FW gill cells might play a role in $\mathrm{Cl}^{-}$transport. The two other validated transcripts, cah4 and $c a h 7$, are protein products known to catalyze the interconversion of carbon dioxide and water to bicarbonate and protons. $\mathrm{CA}$ is recognized to play important roles in gaseous exchanges and the acid-base balance, 


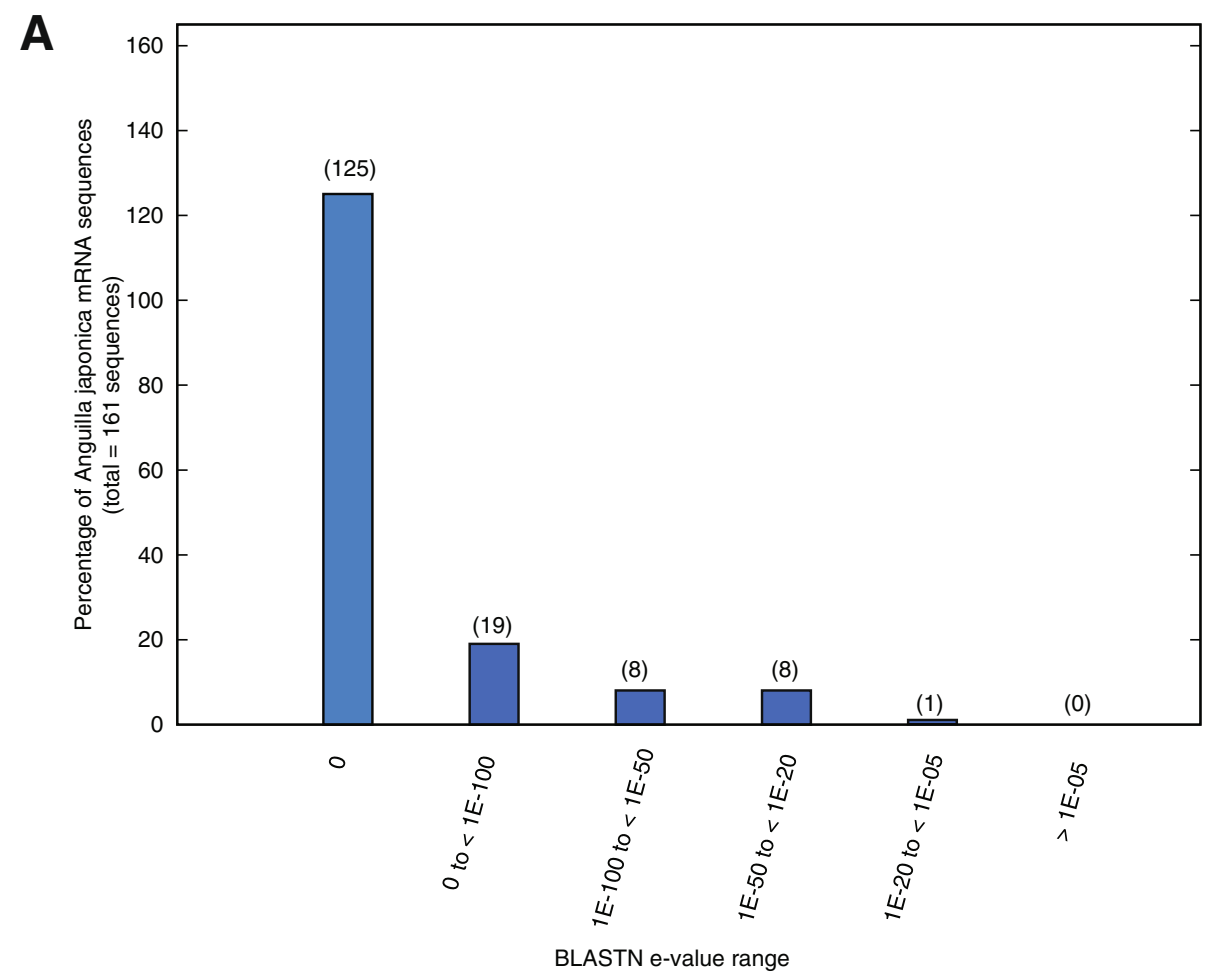

B

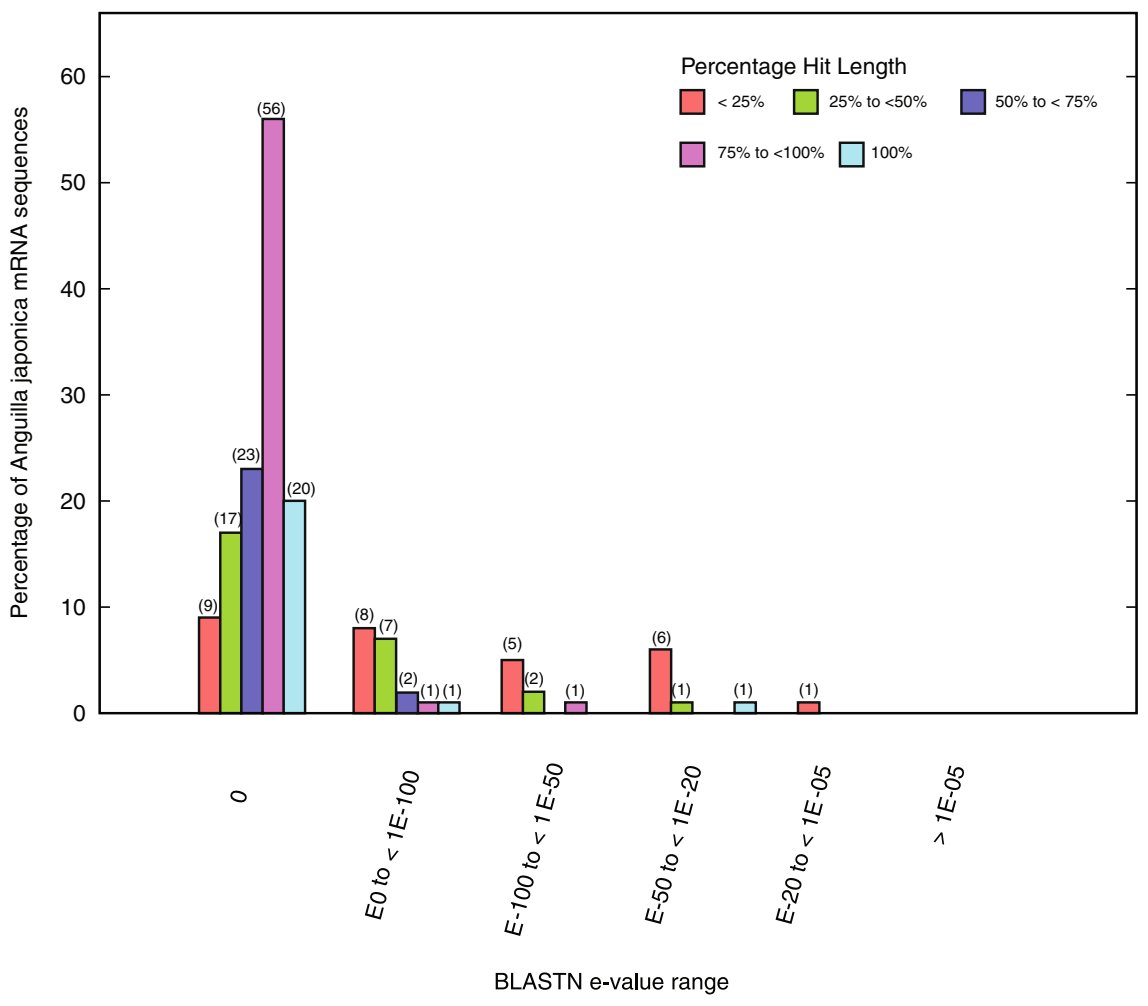

Fig. 3 Evaluation of eel gill cell transcriptome. a Percentage distribution (number) of the 161 Sanger sequences with respective best hit grouped within different BLASTN E-value range. b Percentage distribution (number) of the 161 Sanger sequence with different full-length sizes (bp) grouped within different BLASTN E-value range 


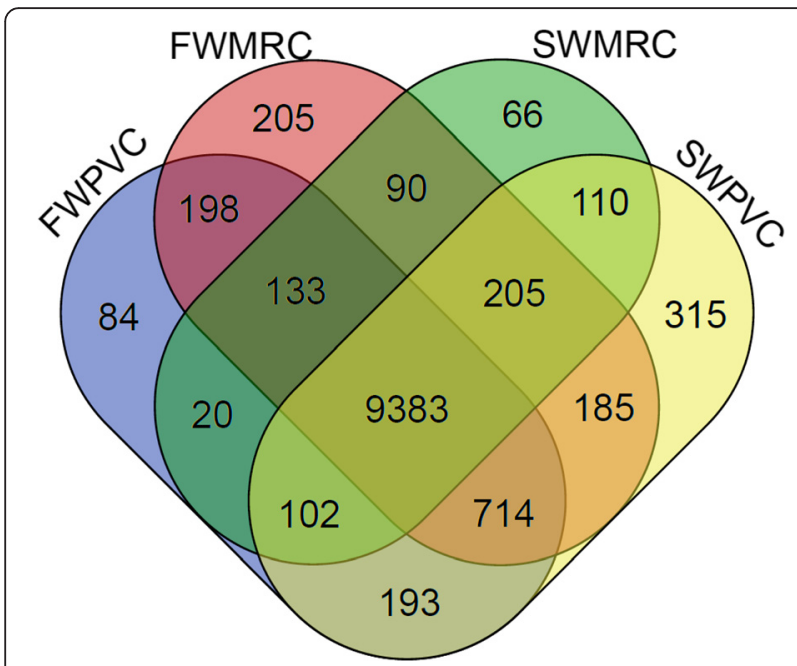

Fig. 4 Comparison of annotated genes in FW PVCs, FW MRCs, SW PVCs, and SW MRCs in eel gills. Of the identified genes, 10,392 transcripts were expressed in PVCs, while 9,811 transcripts were expressed in MRCs

cooperating with other transporters such as sodium hydrogen exchangers (NHEs) in gills of both FW and SW teleost fish [30-33]. Besides, studies have showed that clcn2 was highly expressed in MRCs than PVCs in zebrafish [34]. However, no significant difference was found in the eel gill cells, which may due to the species differences. Nevertheless, we have identified the two CA isoforms differentially expressed in FW and SW environments in this study. The importance of the two isoforms in gaseous exchange and acid-base balance or other functions in FW and SW conditions warrants further investigation (Fig. 5).

\section{Differential expressed genes in PVCs in FW and SW conditions}

To analyze changes in molecular responses in individual cell types, the datasets were processed by comparing the transcriptome of each cell type in FW and SW conditions. Bioinformatics analyses using DAVID and IPA were implemented.

In comparing the transcriptome data of PVCs in FW and SW conditions, 970 DEGs were found. Among those, 401 transcripts were up-regulated and 569 transcripts were down-regulated in FW PVCs as compared to SW PVCs (Fig. 6a; Additional file 4). The highly expressed transcripts detected in FW PVCs were subjected to gene ontology (GO) analysis. The top three categories in the biological process (BP), including (a) intracellular signaling cascade (21 counts), (b) immune response (20 counts), and (c) regulation of cell proliferation (14 counts), were prioritized. For the cellular component (CC), the top three enriched categories were (a) plasma membrane (55 counts), (b) plasma membrane part (34 counts), and (c) cytoplasmic vesicle (11 counts). For the molecular function (MF), the top three categories were (a) transcription regulator activity (23 counts), (b) transcription factor activity (22 counts), and (c) sequence-specific DNA binding (17 counts) (Fig. 6b; Additional file 5). A GO analysis was also conducted using the transcripts that were highly expressed in SW PVCs as compared to FW PVCs. Noticeably, more GO terms were established in the SW PVCs $(290$ v. 122 enriched GO terms), suggesting that the additional enriched gene transcripts participated in specific acclimated functions in the SW environment. In the BP, the top three categories were (a) intracellular signaling cascade (27 counts), (b) phosphate metabolic process/phosphorus metabolic process (21 counts), and (c) regulation of cell proliferation/cell adhesion/biological adhesion (19 counts). In the CC, the top three categories were (a) plasma membrane (58 counts), (b) extracellular region (45 counts), and (c) plasma membrane part (29 counts). In the MF, (a) cation binding (65 counts), (b) metal ion binding (64 counts), and (c) nucleotide binding (39 courts) were the top three in the list (Fig. 6b). In comparison with all 412 GO terms between the FW and SW PVCs, there were only 26 common enriched GO terms (marked in yellow in Additional file 5). Interestingly, in the MF, the insulin-like growth factor (IGF) binding activity and growth factor binding activity were enriched in the SW PVCs. The two binding activities are known to be important in SW acclimation [35]. The GO terms cytoskeletal protein binding and calcium ion binding were also enriched in the SW PVCs, suggesting that cytoskeleton reorganization and calcium ion regulation are essential in SW PVCs. Cytoskeletal reorganization is known to be induced in gill cells upon a hyperosmotic challenge while an increase of $\mathrm{Ca}^{2+}$ binding may facilitate $\mathrm{Ca}^{2+}$ transport and reduce $\mathrm{Ca}^{2+}$-induced cytotoxicity in $\mathrm{SW}$ environments $[18,36]$. Moreover, in the BP, an activation of mitogenactivated protein kinase (MAPK) activity was identified as an enriched GO term in the SW PVCs. This is consistent with our previous studies in indicating the involvement of MAPK cascade in hyperosmotic stresselicited signaling [37, 38]. Lastly, numerous biosynthetic and metabolic regulatory processes were enriched in SW PVCs (Additional file 5), supporting the previous findings of greater metabolic rates detected in gills of SW fish [39].

\section{Differential expressed genes in MRCs in FW and SW conditions}

In the MRCs, 240 transcripts were up-regulated and 160 transcripts were down-regulated in FW conditions as compared to the cells in SW conditions (Fig. 7a; 


\section{cah4}

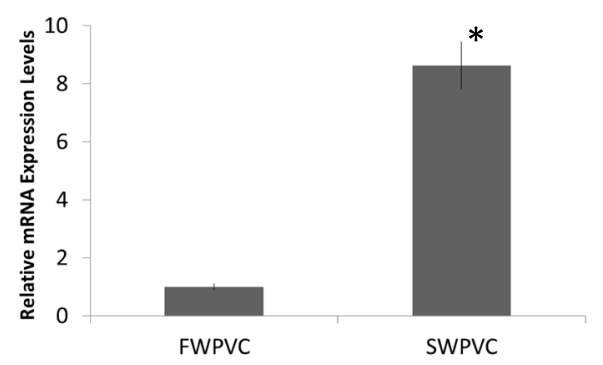

cah7

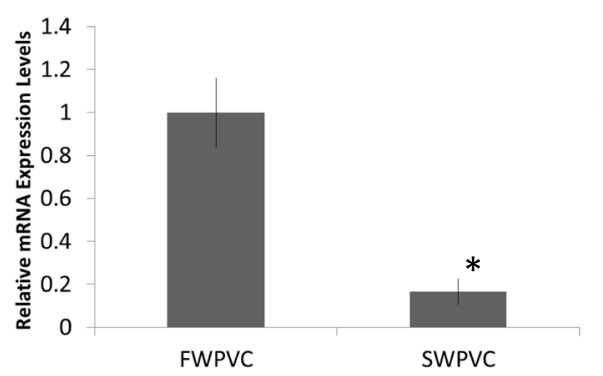

clcn2

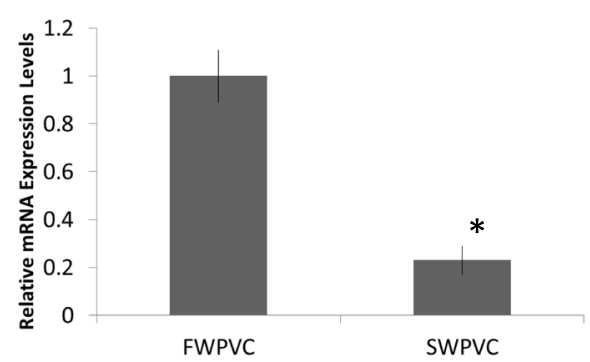

cah4

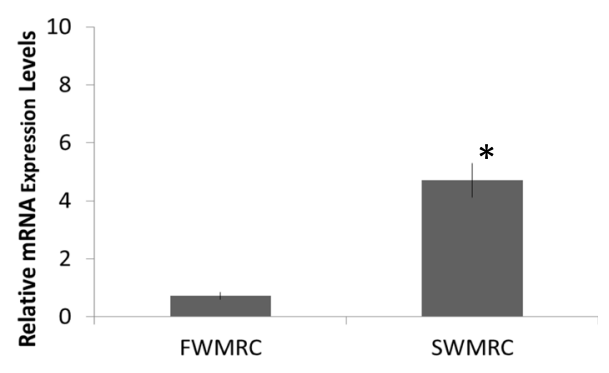

cah7

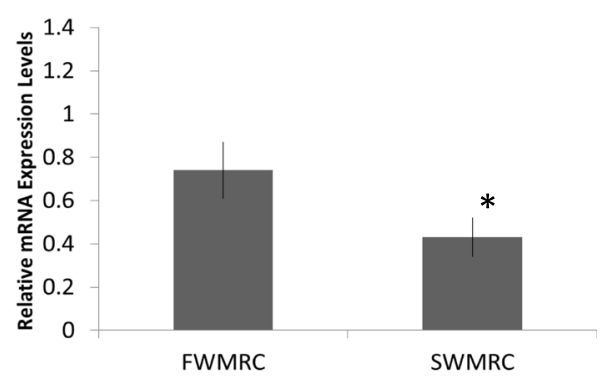

clcn2

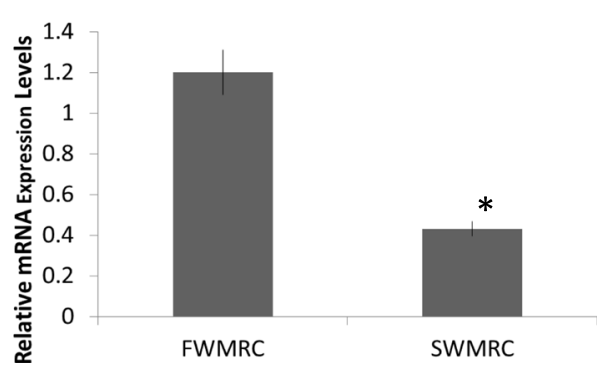

Fig. 5 Quantitative real-time PCR of three selected transcripts. Three transcripts were selected. Carbonic anhydrase 4 (cah4) was highly expressed in SW gill cells, while carbonic anhydrase 7 (cah7) and chloride channel 2 (clcn2) were highly expressed in FW gill cells. * indicated $P<0.05$. All data matched with the RNA-seq result

Additional file 6). In the GO analysis, the top three categories under the BP in the FW MRCs were (a) intracellular signaling cascade (15 counts), (b) immune response (11 counts), and (c) cell adhesion/biological adhesion/cell death/death (8 counts). In the CC, the top three categories on the list were (a) plasma membrane part (21 counts), (b) nucleolus (8 counts), and (c) cell junction ( 7 counts). In the MF, (a) calcium ion binding (9 counts), (b) transcription factor binding (6 counts), and (c) guanyl-nucleotide exchange factor activity/transcription coactivator activity (4 counts) were the three enriched categories (Fig. 7b). While in the SW MRCs, (a) the regulation of cell proliferation/behavior (5 counts) and (b) regulation of cell adhesion/ positive regulation of catalytic activity/positive regulation of molecular function (4 counts) were the top enriched categories in BP. (a) The plasma membrane (19 counts), (b) extracellular region (17 counts), and (c) extracellular region part (10 counts) were the highest on the list under the CC. Notably no MF category was identified in the SW MRCs (Fig. 7b). Collectively, the enriched GO terms in FW MRCs were 45, while in SW MRCs were 28. All identified GO terms were unique in the FW and SW conditions (except "behavior" in BP; marked in yellow in Additional file 7).

Collectively for both cell types in FW and SW conditions, PVCs showed more DEGs and had six-fold more GO terms than the MRCs. The data implied that a greater molecular change was required to modify the functional phenotypes of PVCs in waters of different 


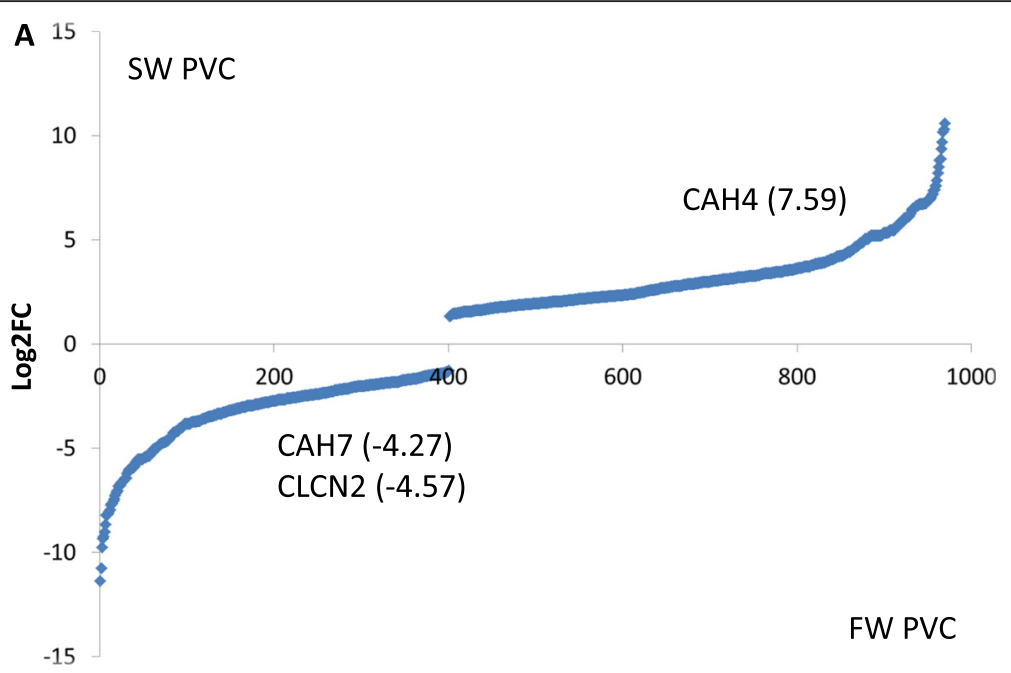

B

FW PVC

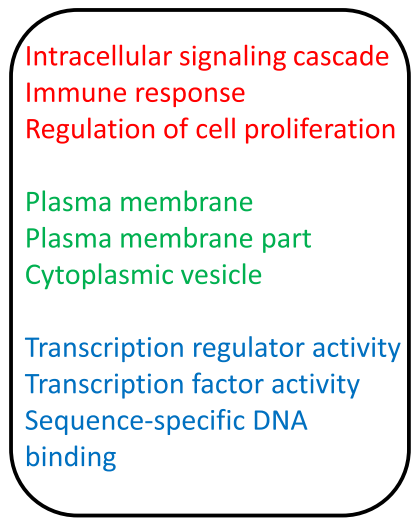

SW PVC

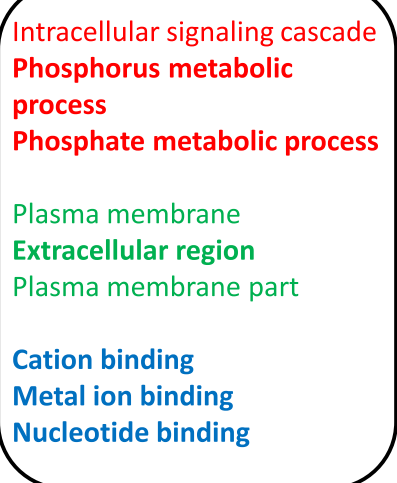

Fig. 6 Summary of the DEGs in FW and SW PVCs. a 401 transcripts expressed higher in FW and 569 transcripts expressed higher in SW. Selected transcripts for validation are indicated. $\mathbf{b}$ The top three enriched GO terms in FW PVCs and SW PVCs. BP appears in red; CC appears in green; MF appears in blue. Bolded text indicates the unique GO terms in FW and SW

salinities. The result is not surprising as the PVCs cover more than $90 \%$ of the outermost layers of fish gills that are in direct contact with water [14].

\section{Differential expressed genes in PVCs and MRCs in FW or SW}

To provide comprehensive data for readers of this report to identify their own targets, we further compared the PVCs and MRCs in FW or SW conditions. One hundred forty-five DEGs were identified in FW conditions, in which 105 transcripts showed higher expressions in MRCs and 40 transcripts were highly expressed in PVCs. While in SW conditions, there were 1439 DEGs in comparison between PVCs and MRCs. Five hundred fortysix transcripts were highly expressed in SW MRCs, while 893 transcripts were expressed higher in SW PVCs (Additional file 8). Highly expressed SW PVC transcripts involved in tight junction and cytoskeleton regulation were selected and real-time PCR was performed for data validation (Additional file 9). The results suggested that in the SW environment, PVCs actively regulate their intra- and inter-cellular architectures to compensate for the SW environment.

\section{PVCs and MRCs showed different osmo-responsive} signaling pathways against osmotic challenges

In the latter part of the analysis, IPA software was used to provide an overview of canonical pathways and cellular functions of the DEGs identified in PVCs or MRCs in both FW and SW conditions (using all the DEGs in PVCs or in MRCs). The cellular locations of the DEGs in PVCs and MRCs were defined. Our results showed that $30 \%$ of the DEGs, either identified in PVCs or MRCs, were localized in "cell cytoplasm" (Fig. 8a). Based 


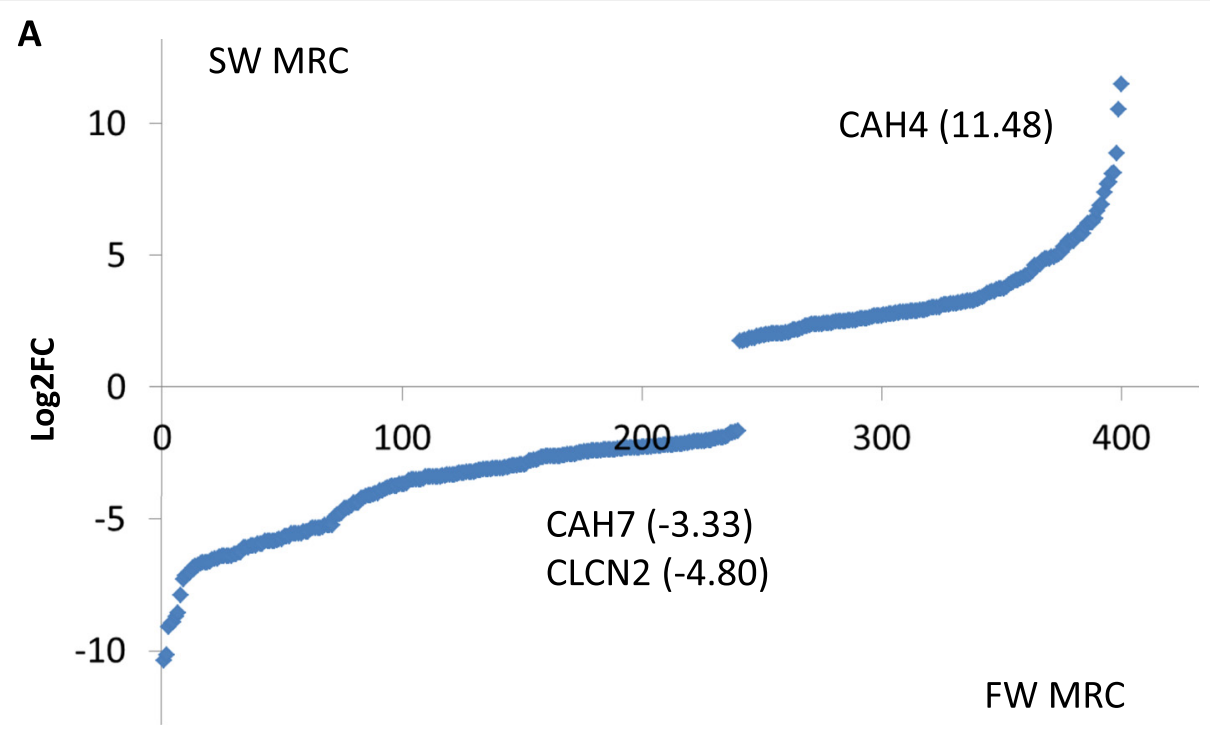

B

FW MRC

SW MRC

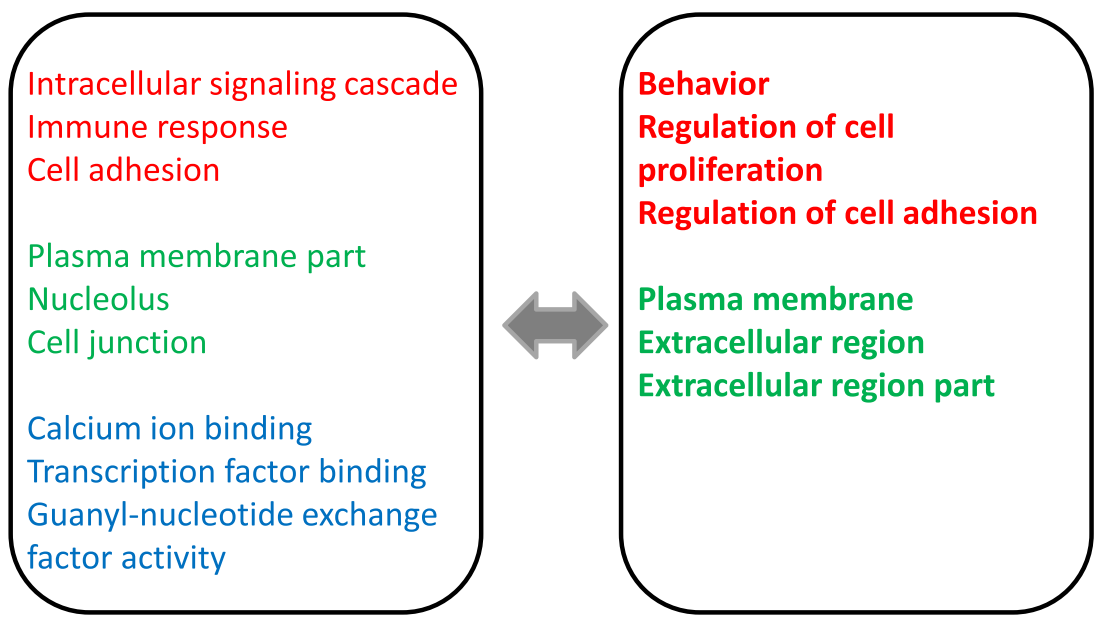

Fig. 7 Summary of the DEGs in FW and SW MRCs. a 241 transcripts expressed higher in FW and 159 transcripts expressed higher in SW. Selected transcripts for validation are indicated. $\mathbf{b}$ The top three enriched GO terms in FW MRCs and SW MRCs. BP appears in red; CC appears in green; MF appears in blue. Bolded text indicates the unique GO terms in FW and SW

on the analysis of functional types of molecules, the two major functional categories (excluding the category "other") observed in both PVCs and MRCs was "enzyme" (18.81 \% in PVCs and $16.4 \%$ in MRCs), and "transcription regulator" (14.4\% in PVCs and $7.26 \%$ in MRCs) (Fig. 8b). We further used the DEGs from PVCs and MRCs to perform the enriched biological function analysis. The data clearly demonstrated that the DEGs in both PVCs and MRCs showed similar cellular functions (Fig. 9; Additional file 10). The number of enriched biological functions in PVCs and MRCs were 20 and 23, respectively, in which 19 of them were in common. PVCs and MRCs were found to participate in different metabolic paths. Carbohydrate metabolism was dominant in PVCs while amino acid and nucleic acid metabolism were prevalent in MRCs. More metabolisms were enriched in the MRCs, which might due to the rich mitochondria content in MRCs. In eels, studies on changing metabolism after treatments were performed in the 1970s [40-42]; however, to our knowledge, there are no studies that specifically focus on the metabolism of the two gill cell types. The suggested data here further supports the combined use of advanced metabolomics studies and the measurement of metabolites in gills to understand the underlying metabolism during osmoregulation. 

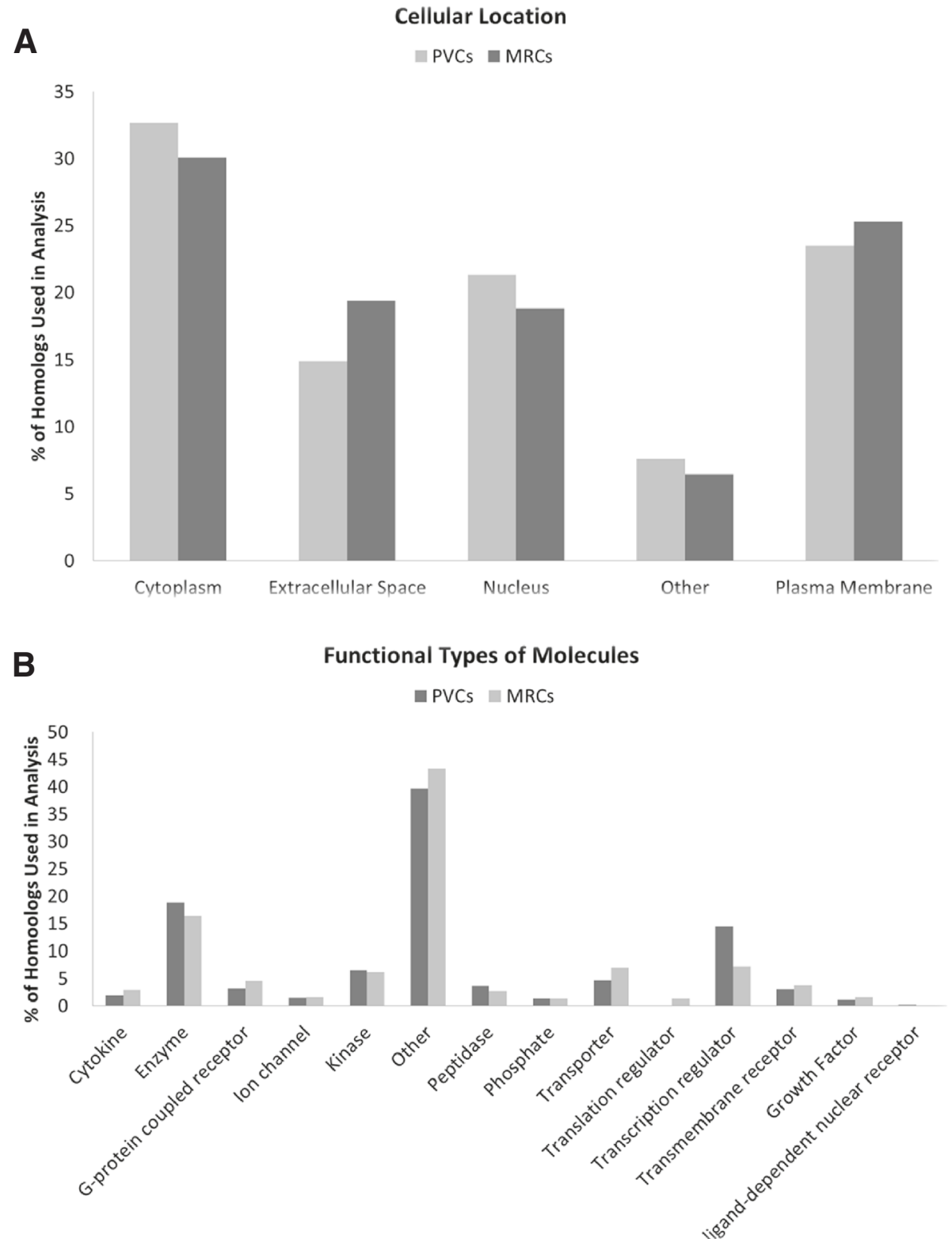

Fig. 8 Functional annotation analyses of the eel gill PVCs and MRCs. a Distribution (percentage of homologs used in analysis) of the putative human homolog encoded proteins with different sub-cellular locations. b Distribution of the putative human homolog encoded proteins according to their functional type

In the enriched pathway analysis, some common and cell-type specific signaling pathways were identified to be activated in PVCs and MRCs during osmotic stress (Fig. 10; Additional file 10). The Janus kinase (JAK)/signal transduction and transcription (STAT) factors, axonal guidance, and Ephrin-B were the common signaling pathways identified in both PVCs and MRCs. The JAK/STAT signaling plays an important role in immunity [43], while our previous proteomics analysis in eel gills underlined the expression of different immune-related proteins upon osmotic stress [44, 45]. The enriched pathway supports the notion that the immune system is involved in fish gill osmoregulation. For the axonal guidance signaling, it is mostly associated with cellular growth, proliferation, and development, and is regulated by the Ephrin-B pathway $[46,47]$. Gill tissues are known to exhibit substantial alterations in epithelial structures and functions in response to changes in water salinity and hardness [35]. This axonal guidance/Ephrin-B pathway may contribute to the proliferation and anatomical localization of PVCs 


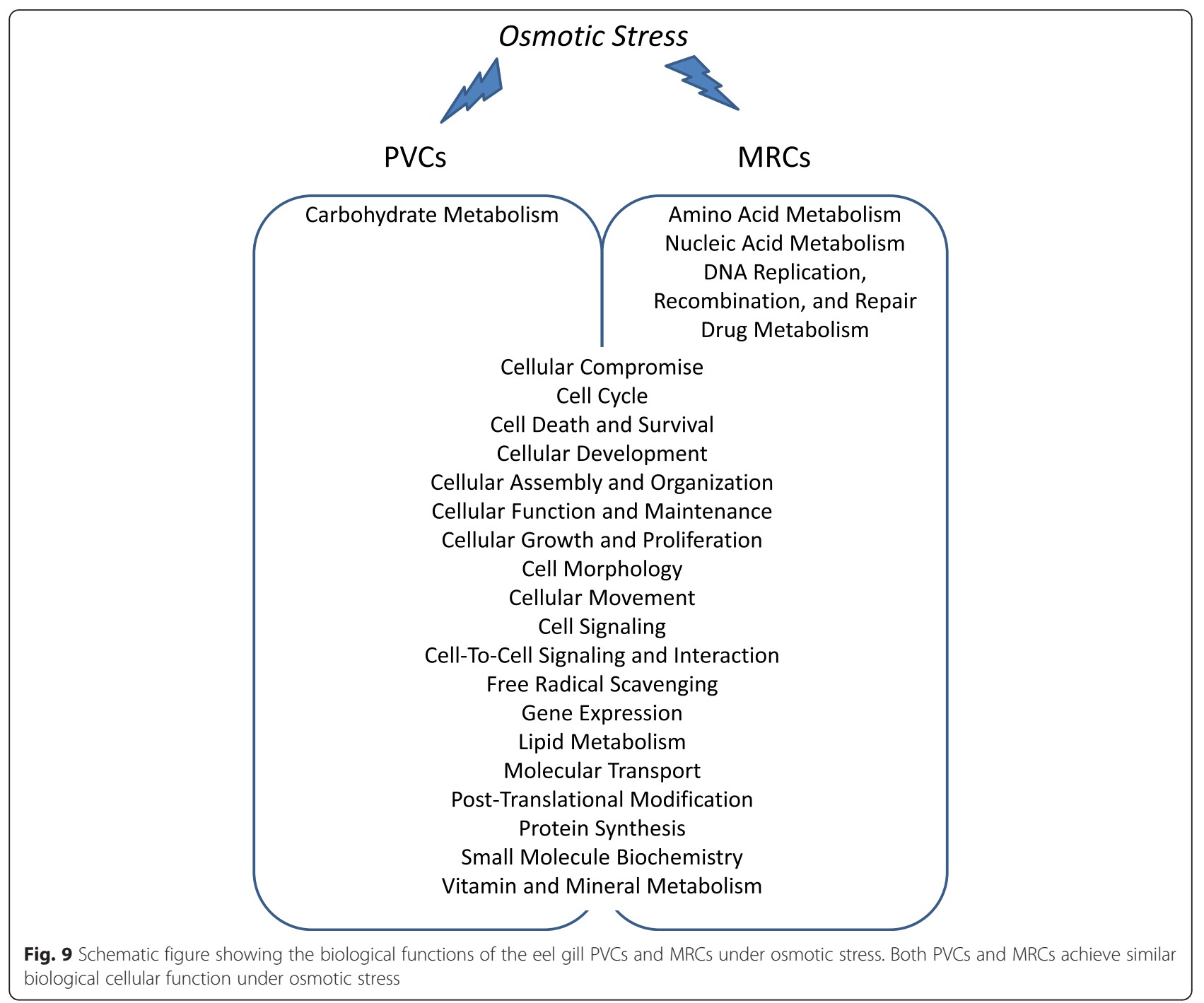

and MRCs to induce functional plasticity of gill tissues to withstand osmotic challenges. In this regard, our finding supports the hypothesis on the "short-term transformation and long-term replacement" in describing gill tissue remodeling processes during early and later phases of acclimation at different water salinities [48].

In addition to the three common signaling pathways, other cell-type specific pathways were identified. PVCs were found to be regulated by two important hormonal pathways, the prolactin signaling and IGF-1 signaling. Prolactin was reported to reduce ion leakage in gills and to play an important role in FW acclimation [35]. It has recently been suggested that prolactin could regulate the expression of the sodium chloride cotransporter via prolactin receptor in zebrafish gills $[49,50]$. The IGF-1 pathway was shown to be involved in SW acclimation $[51,52]$. Moreover, our previous study showed that PVCs were responsive to prolactin or IGF-1 treatment to increase the expression levels of the $\mathrm{Na}^{+} / \mathrm{K}^{+} / \mathrm{Cl}^{-}$cotransporter (NKCC) [53]. In addition to hormonal signaling, the integrin-linked kinase (ILK)-Akt (protein kinase B), cytokine-related pathways such as IL6, and IL8 signaling pathways and hypoxia-inducible factor- $1 \alpha$ $(\mathrm{HIF}-1 \alpha)$ pathways were identified in PVCs. These pathways have been well studied in human carcinogenesis [54-56], but their roles in osmoregulation remain unclear. In addition, the IPA identified the epithelial adherens junction signaling and epithelial mesenchymal transition (EMT) regulatory pathway in PVCs. These identified processes are highly related to cell proliferation/migration, cell-cell interaction, and functional transformation. Cell migration was reported during gill remodeling in fish acclimated in waters of different salinities and hardness [21, 57-59]. In fact, an activation of the Akt pathway was shown to induce the expression of osmotic stress transcription factor 1 (Ostf1) during 


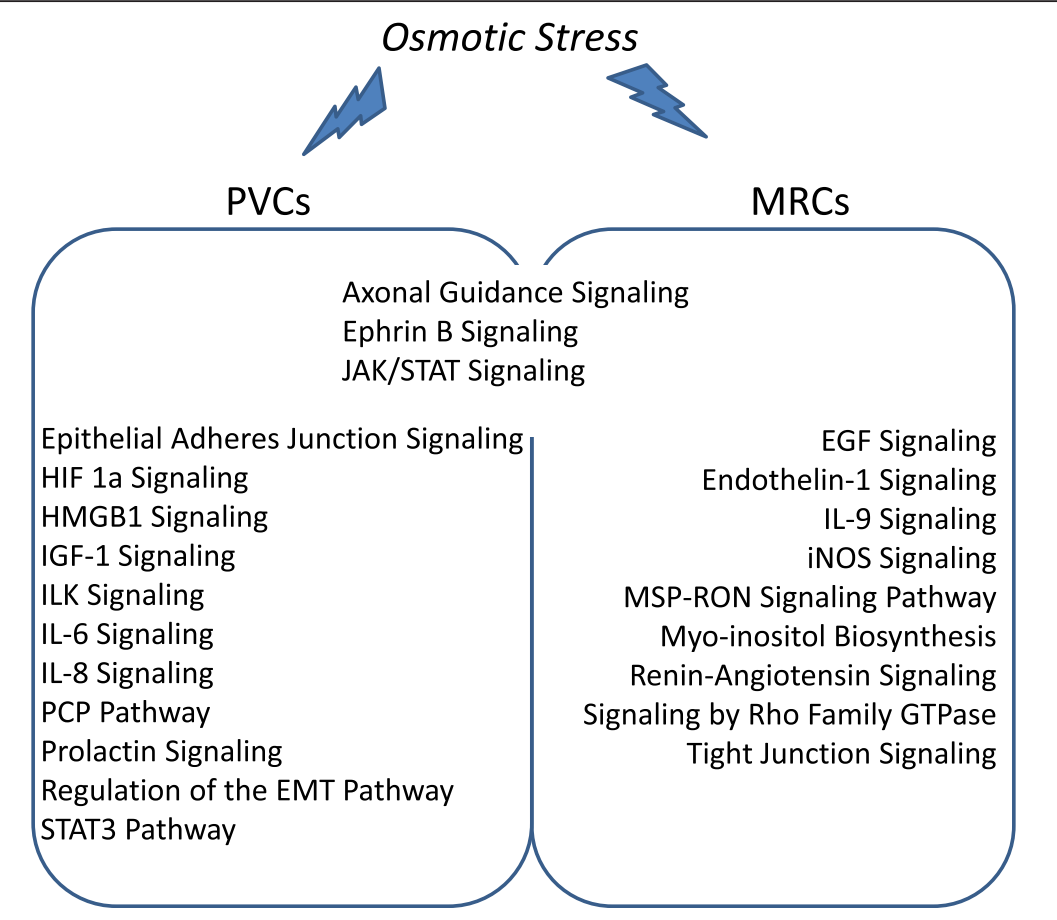

Fig. 10 Schematic figure showing the enriched canonical signaling pathways of the eel gill PVCs and MRCs under osmotic stress. PVCs and MRCs enriched different pathways under osmotic stress

hyperosmotic stress in a PVC culture [44]. The osmoregulatory cytokines, such as tumor necrosis factor $\alpha$ (TNF- $\alpha$ ) and interleukins (ILs), were reported to play roles in the osmotic stress signaling network in fish to regulate epithelial responses to salinity changes $[58,60-62]$.

For MRCs, two other cytokines-related pathways, IL9 and endothelin-1 (EDN1), were recognized. MRCs are well-known for their role in chloride transport [4]. Exogenous EDN1 was reported to regulate chloride transport in the opercular epithelium of killifish; its mRNA expression levels were demonstrated to be increased in gills of killifish during SW acclimation [63]. Moreover EDN1 was recently suggested to inhibit the type A natriuretic peptide receptor, to reduce the expression of nitric oxide synthase (NOS), and to regulate the urinary sodium concentration in rat innermedullary collecting duct cells $[64,65]$. In this regard, NOS was shown to inhibit the expression of sodium pump $\left(\mathrm{Na}^{+} / \mathrm{K}^{+}\right.$-ATPase) in the gills of salmon and trout $[66,67]$. Since the MRCs are featured with a high abundance of $\mathrm{Na}^{+} / \mathrm{K}^{+}$-ATPase, an understanding of the functional roles of EDN1 and NOS in the regulation of $\mathrm{Na}^{+}$-transport in MRCs for osmoregulation is important. In addition, some well-known osmoregulatory pathways like epidermal growth factor (EGF) signaling and renin-angiotensin (RA) signaling were also identified. The EGF signaling pathway is involved in volume and ion regulation [68-70], while the RA signaling is important for epithelial $\mathrm{Na}^{+}$transport and pressor functions [71, 72]. Furthermore, the myo-inositol biosynthesis pathway for the synthesis of a universally compatible osmolyte, myo-inositol [73-77], was found to be enriched. Lastly, the analysis identified the tight junction signaling and Rho GTPase signaling, and the osmotic stress induced Rho pathway has been related to the tight junction rearrangement [78]. It should be noted that the enrichment of a particular pathway is based on the bioinformatics analysis. The DEGs during osmotic stress do not cover all the transcripts that are involved in the pathway, and they can be up- or downregulated. To reach a solid conclusion, researchers must perform further experiments on specific targets.

\section{Conclusion}

Physiological and molecular functions of gill cells have been studied for more than 60 years; however, the molecular responses in the gill PVCs and MRCs in relation to their functional phenotypes remain unclear. Thus, we applied transcriptomic analysis to identify differential expressed transcripts in the two major gill cell types (PVCs and MRCs) in FW- and SW- acclimated eels. The study identifies newly annotated transcripts to enrich the eel gill database, and, for the first time, shows specific osmoregulatory adaptive responses in the PVCs and MRCs. 
We understand that there may be a mis-annotation of eel sequences if using the other available model species databases. Although there are published draft eel genome databases available, such as EeelBase and ZFGenomics, the annotated sequences and confidence reads are still relatively small compared to other model organisms, which have limited the use of these databases for BLAST sequencing. There is a lack of integrated information for accurate bioinformatics prediction. Efforts must be made to facilitate data exchange and communication between different groups after release of a dataset. The presence of highly similar isoforms, or unique eel transcripts could hamper the recent transcriptomic analysis studies; we are looking forward to the completion of the eel genome, which provides the real genome reference of this economically valuable and endangered species.

\section{Method}

\section{Animals and isolation of gill cells}

Japanese eels (Anguilla japonica) weighing 500-600 g were purchased and kept in two $40 \mathrm{~L}$ glass tanks supplied with charcoal-filtered aerated FW or SW (34 ppt) at $18-20{ }^{\circ} \mathrm{C}$ under a $12 \mathrm{~L}: 12 \mathrm{D}$ photoperiod. Ten liters of water was changed every 3 days. The fish $(n=4)$ were sampled after 3 weeks. The fish were anesthetized by $0.1 \%$ MS222 in a plastic container and the gills were perfused with buffered saline $(130 \mathrm{mM} \mathrm{NaCl}, 2.5 \mathrm{mM}$ $\mathrm{KCl}, 5 \mathrm{mM} \mathrm{NaHCO}, 2.5 \mathrm{mM}$ glucose, $2 \mathrm{mM}$ EDTA, and $10 \mathrm{mM}$ Hepes, $\mathrm{pH}$ 7.7) to remove blood cells from gills. Gill arches were excised and washed. The gill arches were cut into small fragments and subjected to two cycles of trypsin digestion (0.5 \% trypsin $+5.3 \mathrm{mM}$ EDTA), each for $20 \mathrm{~min}$ at room temperature in a rotator $(300 \mathrm{rpm})$. The cell suspension was then filtered, washed, and underwent a three-step Percoll gradient of $1.09,1.06$, and $1.03 \mathrm{~g} / \mathrm{ml}$ in PBS and centrifuged at $2,000 \mathrm{~g}$ at $15{ }^{\circ} \mathrm{C}$ for $20 \mathrm{~min}$. Cells at the interface of 1.03 and $1.06 \mathrm{~g} / \mathrm{ml}$ Percoll solution were regarded as PVCs, while at the interface of 1.06 and $1.09 \mathrm{~g} / \mathrm{ml}$ were MRCs. The identity of MRCs was confirmed by mitochondria staining (Mitotracker, CMTMRos- H2, Molecular Probes) and $\mathrm{Na}^{+} / \mathrm{K}^{+}$-ATPase staining (mouse anti- $\mathrm{Na}^{+} / \mathrm{K}^{+}$-ATPase á-subunits antiserum) (1:10, Developmental Studies Hybridoma Bank, the University of Iowa) [21, 38, 79]. The methods were carried out in Hong Kong Baptist University in accordance with the approved guidelines. All experimental procedures were approved by the Hong Kong Baptist University, Hong Kong.

\section{Library construction and Illumina RNA-seq}

The overall workflow of the report is shown in Fig. 1. Briefly, total RNA from FW PVCs, FW MRCs, SW PVCs and SW MRCs (each $n=2$ ) was extracted using the
mirVanaTM miRNA isolation kit (Applied Biosystems). RNA quality was assessed using the Agilent 2100 Bioanalyzer system and samples with a RNA Integrity Number (RIN) greater than 8 were used for RNA library construction. The cDNA libraries were constructed according to manufacturer's instruction and index codes were ligated as identification to individual samples as previous described. Briefly, 8 cDNA libraries were constructed (2 X 4 groups), each prepared from $300 \mathrm{ng}$ of total RNA. mRNA was purified from the total RNA using poly-T oligoattached magnetic beads (Illumina, San Diego, USA) to remove the ribosomal RNA. Then the mRNA was fragmented by using divalent cations in Illumina proprietary fragmentation buffer at $94{ }^{\circ} \mathrm{C}$ for $1 \mathrm{~min}$. First strand cDNAs were synthesized using random oligonucleotides and SuperScript II, then second cDNAs were synthesized using DNA polymerase I and RNase $\mathrm{H}$. Overhangs were blunted by using exonuclease/polymerase, followed by 3' end adenylation. After adenylation of 3' ends of DNA fragments, Illumina PE adapter oligonucleotides were ligated to DNA fragments. DNA fragments that ligated with adaptor molecules on both ends were selectively enriched using Illumina PCR Primer Cocktail in a 15 cycles PCR reaction. Libraries were purified using AMPure XP system and quantified using the KAPA Library Quantification Kits. Before submitted to sequencing, the libraries were normalized and pooled together in a two single lane on an Illumina MiSeq platform and 150 bp paired-end reads were generated. Adapters and reads containing poly- $\mathrm{N}$ were first trimmed and the sequence-reads were dynamically trimmed according to BWA's - q algorithm [80]. Briefly, a running sum algorithm was executed in which a cumulative area-plot is plotted from 3'-end to the 5'-end of the sequence reads and where positions with a basecalling Phred quality lower than 30 cause an increase of the area and vice versa. Such plot was built for each read individually and each read was trimmed from the 3'-end to the position where the area was greatest. Read-pairs were then synchronized such that all read-pairs with sequence on both sides longer than 35 bp after quality trimming were retained. Any singleton read resulting from read trimming was removed [80]. All the downstream analyses were based on quality trimmed reads.

\section{De novo Transcriptome assembly}

Forward and reverse reads from all the libraries/samples were pooled and subjected to transcriptome de novo assembly using Trinity (version r20140413p1) with "min_kmer_cov" set to 2; "SS_lib_type" set to RF, and all other parameters set to default [81]. Trinity uses fixed k-mer to generate an assembly and it is efficient in recovering full-length transcripts as well as spliced isoforms. 


\section{Annotation of assembled transcripts}

Coding sequences (open reading frames, ORF) were identified by Transdecoder [82] using the following criteria: (1) the longest ORF was identified within each transcript; (2) from the longest ORFs extracted, a subset of the longest ones was identified and randomized to provide a sequence composition corresponding to noncoding sequences before being used to parameterize a Markov model based on hexamers; and (3) all the longest ORFS were scored according to the Markov Model to identify the highest scoring reading-frame out of the six possible reading-frames. These ORF were then translated to protein sequences and subjected to (1) BLASTp search against UniProtKB/Swiss-Prot with a cut-off e-value $[83,84]$ of $1.0 \times 10^{-6}$, (2) protein domain search via HMMScan, (3) transmembrane helicase prediction by TMHMM, and (4) signal peptide prediction by SignalP.

\section{Comparative analysis of 454 and MiSeq assembled eel gill transcriptome}

The eel gill transcriptome of whole gill samples generated by 454 platform was obtained [17]. The transcripts generated by MiSeq and 454 were considered to be the same transcript if they were the symmetrical best hits in each reciprocal all-against-all BLASTn search (i.e. Reciprocal Best Hit [85]). Briefly, putative match to the 454 sequences were identified first by comparing the MiSeq assembled transcript to the 454 database using BLASTn search. The highest-scoring hit was obtained and, then, a BLASTn search was run against the database of the assembled transcripts. The hit in 454 sequences was considered an identical transcript of the assembled transcript if and only if the second BLAST search returned the assembled transcript that was the highest scorer in the first BLAST search. mRNA transcripts with complete coding sequence of Anguilla species were retrieved from NCBI using search term (Anguilla japonica[porgn] AND (complete[All Fields] AND cds[All Fields])).

\section{Differential expression, GO and pathway enrichment analysis}

Differential gene expression and TMM-normalized FPKM gene expression were calculated by RSEM pipeline using edgeR package [86]. Samples with identical treatments were considered to be biological replicates. Genes with B\&H corrected $p$-value $<0.05$ and $\log 2$ (fold change) $>1$ were considered be statistically significant differentially expressed. The Database for Annotation, Visualization and Integrated Discovery (DAVID) was used for functional annotation clustering analysis on the all samples comparison (FW PVCs Vs SW PVCs/FW MRCs Vs SW MRCs) with the classification stringency as Benjamini-Hochberg corrected $P$-value $(P<0.05)$ [87]. The dysregulated transcripts (FW PVCs Vs SW PVCs and FW MRCs Vs SW MRCs) with human homologs of the assembled contigs were then underwent the IPA software to identify functional canonical pathways and functions (www.qiagen.com/ingenuity) with the significance level set at Benjamini-Hochberg corrected $P$-value $(P<0.05)$.

\section{Real-time PCR analysis}

The isolated enriched PVCs or MRCs were dissolved in Tri-Reagent (Gibco-BRL) for total RNA extraction. Total RNA with a ratio of 1.8-2.0 at A260/A280 was used for cDNA synthesis. Briefly, $0.5 \mu \mathrm{g}$ total cellular RNA was reverse transcribed by VILO (Invitrogen). PCR was conducted using the Applied Biosystems 7500 real-time PCR detection system using KAPA SYBR ${ }^{\circ}$ Green Supermix (KAPA). Primers used in the real-time PCR assay were designed on the basis of transcriptome sequence. Sequences of the real-time PCR primers were tabulated in Additional file 11. The data were then normalized using the expression levels of gapdh mRNA [88]. The existence of primer-dimers and secondary products was checked using melting curve analysis. Our data indicated that the amplification was specific. Only one PCR product was amplified for each individual primer set. The relative expression ratio was calculated according to the method described by Pfaffl [89].

\section{Availability of supporting data}

The sequencing data from this study have been submitted to the NCBI Sequence Read Archive (SRA) (http:// www.ncbi.nlm.nih.gov/ sra) under the accession number SRP049703. Other data supporting the result of this article are included within the article and the Additional files 1, $2,3,4,5,6,7,8,9,10,11$.

\section{Additional files}

Additional file 1: List of 12,003 identified transcripts in eel gill cells. (XLSX 28990 kb)

Additional file 2: Taxonomic distribution of the 12,003 identified eel gill transcripts. (XLSX $9 \mathrm{~kb}$ )

Additional file 3: Comparison of the present cell-type specific transcriptome data to our previous whole-gill tissue transcriptome. (XLSX $1505 \mathrm{~kb})$

Additional file 4: List of the 970 DEGs identified from FW PVCs and SW PVCs. (XLSX $117 \mathrm{~kb}$ )

Additional file 5: Gene ontology of DEGs identified from FW PVCs and SW PVCs. (XLSX 29 kb)

Additional file 6: List of the 400 DEGs identified from FW PVCs and SW PVCs. (XLSX $51 \mathrm{~kb}$ )

Additional file 7: Gene ontology of DEGs identified from FW MRCs and SW MRCs. (XLSX $13 \mathrm{~kb}$ )

Additional file 8: List of DEGs identified from FW MRCs and FW PVCs, and SW MRCs and SW PVCs. (XLSX $173 \mathrm{~kb}$ ) 


\section{Additional file 9: Real-time PCR of selected SW PVC highly expressed transcripts that contributed to the tight junction and cytoskeleton reorganization. (PDF $279 \mathrm{~kb}$ ) \\ Additional file 10: Ingenuity pathway analysis of the DEGs identified from PVCs or MRCs. (PDF $253 \mathrm{~kb}$ ) \\ Additional file 11: Primers for real-time PCR of selected genes. (XLSX $11 \mathrm{~kb})$}

\section{Competing interests}

The authors declare that they have no competing interests.

\section{Authors' contributions}

Conceived and designed the experiments: WKFT CKCW. Performed the experiments: KPL GJ WKFT. Analysed the data: KPL JWL TFC WKFT CKCW. Wrote the paper: KPL JWL WKFT CKCW. All authors read and approved the final manuscript.

\section{Acknowledgement}

This work was supported by the General Research Fund (GRF261610) to CKCW; and the Faculty Start-up Fund, Hong Kong Baptist University (BIOL3840101) to WKFT. JWL and TFC are supported by the Lo Kwee-Seong Biomedical Research Fund and the Lee Hysan Foundation.

\section{Author details}

${ }^{1}$ School of Biological Sciences, Kadoorie Biological Sciences Building, The University of Hong Kong, Pokfulam Road, Pok Fu Lam, Hong Kong. ${ }^{2}$ State Key Laboratory of Agrobiotechnology, The Chinese University of Hong Kong, Shatin, Hong Kong. ${ }^{3}$ Faculty of Medicine, The Chinese University of Hong Kong, Shatin, Hong Kong. ${ }^{4}$ Department of Biology, Hong Kong Baptist University, Kowloon Tong, Hong Kong. ${ }^{5}$ Croucher Institute for Environmental Sciences, Hong Kong Baptist University, Pok Fu Lam, Hong Kong.

Received: 29 June 2015 Accepted: 3 December 2015

Published online: 18 December 2015

\section{References}

1. Hwang PP, Lee TH, Lin LY. Ion regulation in fish gills: recent progress in the cellular and molecular mechanisms. Am J Physiol Regul Integr Comp Physiol. 2011:301(1):R28-47.

2. Mizuhira V, Amakawa T, Yamashina S, Shirai N, Utida S. Electron microscopic studies on the localization of sodium ions and sodium-potassium-activated adenosinetriphosphatase in chloride cells of eel gills. Exp Cell Res. 1970; 59(2):346-8.

3. Utida S, Kamiya M, Shirai N. Relationship between the activity of Na+-K +-activated adenosinetriphosphatase and the number of chloride cells in eel gills with special reference to sea-water adaptation. Comp Biochem Physiol A Comp Physiol. 1971; 38(2): 443-7.

4. Karnaky Jr KJ, Degnan KJ, Zadunaisky JA. Chloride transport across isolated opercular epithelium of killifish: a membrane rich in chloride cells. Science (New York, NY). 1977;195(4274):203-5.

5. Foskett JK, Machen TE, Bern HA. Chloride secretion and conductance of teleost opercular membrane: effects of prolactin. Am J Physiol. 1982;242(3):R380-9.

6. Pelis RM, Zydlewski J, McCormick SD. Gill Na(+)-K(+)-2Cl(-) cotransporter abundance and location in Atlantic salmon: effects of seawater and smolting. Am J Physiol Regul Integr Comp Physiol. 2001;280(6):R1844-52.

7. Catches JS, Burns JM, Edwards SL, Claiborne JB. Na+/H+ antiporter, $\mathrm{V}-\mathrm{H}+-$ ATPase and $\mathrm{Na}+/ \mathrm{K}+-$ ATPase immunolocalization in a marine teleost (Myoxocephalus octodecemspinosus). J Exp Biol. 2006;209(Pt 17):3440-7.

8. Kalujnaia S, McWilliam IS, Zaguinaiko VA, Feilen AL, Nicholson J, Hazon N, et al. Transcriptomic approach to the study of osmoregulation in the European eel Anguilla anguilla. Physiol Genomics. 2007:31(3):385-401.

9. Kalujnaia S, McWilliam IS, Zaguinaiko VA, Feilen AL, Nicholson J, Hazon N, et al. Salinity adaptation and gene profiling analysis in the European eel (Anguilla anguilla) using microarray technology. Gen Comp Endocrinol. 2007:152(2-3):274-80.

10. Fiol DF, Kultz D. Rapid hyperosmotic coinduction of two tilapia (Oreochromis mossambicus) transcription factors in gill cells. Proc Natl Acad Sci U S A. 2005;102(3):927-32.
11. Takei $Y$, Hiroi J, Takahashi H, Sakamoto T. Diverse mechanisms for body fluid regulation in teleost fishes. Am J Physiol Regul Integr Comp Physiol. 2014; 307(7):R778-92.

12. Girard JP, Payan P. Ion exchanges through respiratory and chloride cells in freshwater- and seawater-adapted teleosteans. Am J Physiol. 1980;238(3):R260-8.

13. Perry SF. The chloride cell: Structure and function in the gills of freshwater fishes. Annu Rev Physiol. 1997;59:325-47.

14. Wilson JM, Laurent P. Fish gill morphology: inside out. J Exp Zool. 2002; 293(3):192-213.

15. Henkel CV, Dirks RP, de Wijze DL, Minegishi Y, Aoyama J, Jansen HJ, et al. First draft genome sequence of the Japanese eel, Anguilla japonica. Gene. 2012;511(2):195-201.

16. Coppe A, Pujolar JM, Maes GE, Larsen PF, Hansen MM, Bernatchez L, et al. Sequencing, de novo annotation and analysis of the first Anguilla anguilla transcriptome: EeelBase opens new perspectives for the study of the critically endangered european eel. BMC Genomics. 2010;11.

17. Tse WKF, Sun J, Zhang H, Law AYS, Yeung BHY, Chow SC, et al. Transcriptomic and iTRAQ proteomic approaches reveal novel short-term hyperosmotic stress responsive proteins in the gill of the Japanese eel (Anguilla japonica). J Proteomics. 2013;89:81-94

18. Gu J, Li JW, Tse WK, Chan TF, Lai KP, Wong CK. Transcriptomic responses of corpuscle of Stannius gland of Japanese eels (Anguilla japonica) to Changes in Water Salinity. Sci Rep. 2015;5:9836.

19. Lam SH, Lui EY, Li Z, Cai S, Sung WK, Mathavan S, et al. Differential transcriptomic analyses revealed genes and signaling pathways involved in iono-osmoregulation and cellular remodeling in the gills of euryhaline Mozambique tilapia. Oreochromis mossambicus. BMC Genomics. 2014;15:921.

20. Wong CKC, Chan DKO. Isolation of viable cell types from the gill epithelium of Japanese eel Anguilla japonica. Am J Physiol Regul Integr Comp Physiol. 1999:276(2):R363-72.

21. Tse WKF, Au DWT, Wong CKC. Characterization of ion channel and transporter mRNA expressions in isolated gill chloride and pavement cells of seawater acclimating eels. Biochem Biophys Res Commun. 2006;346(4): 1181-90.

22. Goss GG, Adamia S, Galvez F. Peanut lectin binds to a subpopulation of mitochondria-rich cells in the rainbow trout gill epithelium. Am J Physiol Regul Integr Comp Physiol. 2001;281(5):R1718-25.

23. Galvez F, Reid SD, Hawkings G, Goss GG. Isolation and characterization of mitochondria-rich cell types from the gill of freshwater rainbow trout. Am J Physiol Regul Integr Comp Physiol. 2002;282(3):R658-68.

24. Wong CKC, Chan DKO. Chloride cell subtypes in the gill epithelium of Japanese eel Anguilla japonica. Am J Physiol Regul Integr Comp Physiol. 1999:277(2):R517-22

25. Wong CK, Chan DK. Effects of cortisol on chloride cells in the gill epithelium of Japanese eel, Anguilla japonica. J Endocrinol. 2001;168(1):185-92.

26. Schiffhauer ES, Vij N, Kovbasnjuk O, Kang PW, Walker D, Lee S, et al. Dual activation of CFTR and CLCN2 by lubiprostone in murine nasal epithelia. Am J Physiol Lung Cell Mol Physiol. 2013;304(5):L324-31.

27. Stolting G, Fischer M, Fahlke C. CLC channel function and dysfunction in health and disease. Front Physiol. 2014;5:378.

28. Guh Y, Lin C, Hwang P. Osmoregulation in zebrafish: ion transport mechanisms and functional regulation. EXCLI Journal. 2015;14:627-59.

29. Wang YF, Yan JJ, Tseng YC, Chen RD, Hwang PP. Molecular Physiology of an Extra-renal $\mathrm{Cl}(-)$ Uptake Mechanism for Body Fluid $\mathrm{Cl}(-)$ Homeostasis. Int J Biol Sci. 2015;11(10):1190-203.

30. Haswell MS, Randall DJ, Perry SF. Fish gill carbonic anhydrase: acid-base regulation or salt transport? Am J Physiol. 1980;238(3):R240-5.

31. Randall DJ, Brauner C. Interactions between ion and gas transfer in freshwater teleost fish. Comp Biochem Physiol A Mol Integr Physiol. 1998;119(1):3-8.

32. Rahim SM, Delaunoy JP, Laurent P. Identification and immunocytochemical localization of two different carbonic anhydrase isoenzymes in teleostean fish erythrocytes and gill epithelia. Histochemistry. 1988:89(5):451-9.

33. Gilmour KM. New insights into the many functions of carbonic anhydrase in fish gills. Respir Physiol Neurobiol. 2012;184(3):223-30.

34. Lin TY, Liao BK, Horng JL, Yan JJ, Hsiao CD, Hwang PP. Carbonic anhydrase 2-like a and 15a are involved in acid-base regulation and $\mathrm{Na}+$ uptake in zebrafish H+-ATPase-rich cells. Am J Physiol Cell Physiol. 2008;294(5): C1250-60.

35. Evans DH, Piermarini PM, Choe KP. The multifunctional fish gill: Dominant site of gas exchange, osmoregulation, acid-base regulation, and excretion of nitrogenous waste. Physiol Rev. 2005;85(1):97-177. 
36. Gu J, Law AY, Yeung BH, Wong CK. Activation of gill Ca2 +-sensing receptor as a protective pathway to reduce Ca2 + -induced cytotoxicity. J Mol Endocrinol. 2014;53(2):155-64.

37. Chow SC, Wong CKC. Regulatory function of hyperosmotic stress-induced signaling cascades in the expression of transcription factors and osmolyte transporters in freshwater Japanese eel primary gill cell culture. J Exp Biol. 2011;214(8):1264-70

38. Tse WKF, Chow SC, Wong CKC. Eel osmotic stress transcriptional factor 1 (Ostf1) is highly expressed in gill mitochondria-rich cells, where ERK phosphorylated. Frontiers in Zoology. 2012;9.

39. Zikos A, Seale AP, Lerner DT, Grau EG, Korsmeyer KE. Effects of salinity on metabolic rate and branchial expression of genes involved in ion transport and metabolism in Mozambique tilapia (Oreochromis mossambicus). Comp Biochem Physiol A Mol Integr Physiol. 2014;178:121-31.

40. Chan DK, Woo NY. Effect of cortisol on the metabolism of the eel, Anguilla japonica. Gen Comp Endocrinol. 1978;35(3):205-15.

41. Chan DK, Woo NY. The respiratory metabolism of the Japanese eel, Anguilla japonica: effects of ambient oxygen, temperature, season, body weight, and hypophysectomy. Gen Comp Endocrinol. 1978;35(2):160-8.

42. Chan DK, Woo NY. Effect of hypophysectomy on the chemical composition and intermediary metabolism of the Japanese eel, Anguilla japonica. Gen Comp Endocrinol. 1978;35(2):169-78.

43. Zou J, Secombes CJ. Teleost fish interferons and their role in immunity. Dev Comp Immunol. 2011;35(12):1376-87

44. Chow SC, Tse WKF, Wong CKC. Dexamethasone (DEX) induces Osmotic stress transcription factor 1 (Ostf1) through the Akt-GSK3 beta pathway in freshwater Japanese eel gill cell cultures. Biology Open. 2013;2(5):487-91.

45. Tse WKF, Sun J, Zhang HM, Lai KP, Gu J, Qiu JW, et al. iTRAQ-based quantitative proteomic analysis reveals acute hypo-osmotic responsive proteins in the gills of the Japanese eel (Anguilla japonica). J Proteomics. 2014;105:133-43.

46. Egea J, Klein R. Bidirectional Eph-ephrin signaling during axon guidance. Trends Cell Biol. 2007;17(5):230-8.

47. Chilton JK. Molecular mechanisms of axon guidance. Dev Biol. 2006; 292(1):13-24.

48. Katoh F, Kaneko T. Short-term transformation and long-term replacement of branchial chloride cells in killifish transferred from seawater to freshwater, revealed by morphofunctional observations and a newly established 'time-differential double fluorescent staining' technique. J Exp Biol. 2003;206(22):4113-23.

49. Breves JP, Serizier SB, Goffin V, McCormick SD, Karlstrom RO. Prolactin regulates transcription of the ion uptake $\mathrm{Na}+/ \mathrm{Cl}$ - cotransporter (ncc) gene in zebrafish gill. Mol Cell Endocrinol. 2013;369(1-2):98-106

50. Breves JP, McCormick SD, Karlstrom RO. Prolactin and teleost ionocytes: new insights into cellular and molecular targets of prolactin in vertebrate epithelia. Gen Comp Endocrinol. 2014;203:21-8.

51. McCormick SD, Bradshaw D. Hormonal control of salt and water balance in vertebrates. Gen Comp Endocrinol. 2006;147(1):3-8

52. McCormick SD, Dickhoff WW, Duston J, Nishioka RS, Bern HA. Developmental differences in the responsiveness of gill $\mathrm{Na}+, \mathrm{K}(+)$-ATPase to cortisol in salmonids. Gen Comp Endocrinol. 1991;84(2):308-17.

53. Tse WKF, Au DWT, Wong CKC. Effect of osmotic shrinkage and hormones on the expression of $\mathrm{Na}+/ \mathrm{H}+$ exchanger- $1, \mathrm{Na}+/ \mathrm{K}+/ 2 \mathrm{Cl}(-)$ cotransporter and $\mathrm{Na}+/ \mathrm{K}+-$ ATPase in gill pavement cells of freshwater adapted Japanese eel, Anguilla japonica. J Exp Biol. 2007;210(12):2113-20.

54. Chang LH, Pan SL, Lai CY, Tsai AC, Teng CM. Activated PAR-2 regulates pancreatic cancer progression through ILK/HIF-alpha-induced TGF-alpha expression and MEKNEGF-A-mediated angiogenesis. Am J Pathol. 2013;183(2):566-75.

55. Tseng WP, Yang SN, Lai CH, Tang CH. Hypoxia induces BMP-2 expression via ILK, Akt, mTOR, and HIF-1 pathways in osteoblasts. J Cell Physiol. 2010;223(3):810-8.

56. Tan C, Cruet-Hennequart S, Troussard A, Fazli L, Costello P, Sutton K, et al. Regulation of tumor angiogenesis by integrin-linked kinase (ILK). Cancer Cell. 2004:5(1):79-90

57. Mitrovic D, Dymowska A, Nilsson GE, Perry SF. Physiological consequences of gill remodeling in goldfish (Carassius auratus) during exposure to long-term hypoxia. Am J Physiol Regul Integr Comp Physiol. 2009;297(1):R224-34.

58. Kultz D. The combinatorial nature of osmosensing in fishes. Physiology (Bethesda). 2012;27(4):259-75.
59. Lai KP, Law AYS, Lau MCC, Takei Y, Tse WKF, Wong CKC. Osmotic stress transcription factor 1b (Ostf1b) promotes migration properties with the modulation of epithelial mesenchymal transition (EMT) phenotype in human embryonic kidney cell. International Journal of Biochemistry \& Cell Biology. 2013;45(8):1921-6.

60. Fiol DF, Chan SY, Kultz D. Identification and pathway analysis of immediate hyperosmotic stress responsive molecular mechanisms in tilapia (Oreochromis mossambicus) gill. Comp Biochem Physiol Part D Genomics Proteomics. 2006;1 (3):344-56.

61. Papakostas S, Vasemagi A, Vaha JP, Himberg M, Peil L, Primmer CR. A proteomics approach reveals divergent molecular responses to salinity in populations of European whitefish (Coregonus lavaretus). Mol Ecol. 2012;21(14):3516-30.

62. Dowd WW, Harris BN, Cech Jr JJ, Kultz D. Proteomic and physiological responses of leopard sharks (Triakis semifasciata) to salinity change. J Exp Biol. 2010;213(2):210-24.

63. Hyndman KA, Evans DH. Endothelin and endothelin converting enzyme-1 in the fish gill: evolutionary and physiological perspectives. J Exp Biol. 2007;210(Pt 24):4286-97.

64. Chen S, Cao L, Intengan HD, Humphreys M, Gardner DG. Osmoregulation of endothelial nitric-oxide synthase gene expression in inner medullary collecting duct cells. Role in activation of the type A natriuretic peptide receptor. J Biol Chem. 2002;277(36):32498-504.

65. Ye Q, Chen S, Gardner DG. Endothelin inhibits NPR-A and stimulates eNOS gene expression in rat IMCD cells. Hypertension. 2003;41(3 Pt 2):675-81.

66. Ebbesson LO, Tipsmark CK, Holmqvist B, Nilsen T, Andersson E, Stefansson SO, et al. Nitric oxide synthase in the gill of Atlantic salmon: colocalization with and inhibition of Na+, K+ -ATPase. J Exp Biol. 2005;208(Pt 6):1011-7.

67. Tipsmark CK, Madsen SS. Regulation of $\mathrm{Na}+/ \mathrm{K}+-$ ATPase activity by nitric oxide in the kidney and gill of the brown trout (Salmo trutta). J Exp Biol. 2003;206(Pt 9):1503-10.

68. Kuper C, Steinert D, Fraek ML, Beck FX, Neuhofer W. EGF receptor signaling is involved in expression of osmoprotective TonEBP target gene aldose reductase under hypertonic conditions. Am J Physiol Renal Physiol. 2009;296(5):F1100-8.

69. Browe DM, Baumgarten CM. EGFR kinase regulates volume-sensitive chloride current elicited by integrin stretch via PI-3 K and NADPH oxidase in ventricular myocytes. J Gen Physiol. 2006;127(3):237-51.

70. Barisic K, Karuzic O, Petrik J, Grubisic TZ. Regulation of Na+/H+ exchanger by urogastrone, a potent activator of cell proliferation. Physiological research / Academia Scientiarum Bohemoslovaca. 2002;51(5):483-91.

71. Marsigliante S, Muscella A, Vinson GP, Storelli C. Angiotensin II receptors in the gill of sea water- and freshwater-adapted eel. J Mol Endocrinol. 1997;18(1):67-76.

72. Tierney ML, Luke G, Cramb G, Hazon N. The role of the renin-angiotensin system in the control of blood pressure and drinking in the European eel, Anguilla anguilla. Gen Comp Endocrinol. 1995;100(1):39-48.

73. Kalujnaia S, Gellatly SA, Hazon N, Villasenor A, Yancey PH, Cramb G. Seawater acclimation and inositol monophosphatase isoform expression in the European eel (Anguilla anguilla) and Nile tilapia (Orechromis niloticus). Am J Physiol Regul Integr Comp Physiol. 2013;305(4):R369-84.

74. Kalujnaia S, McVee J, Kasciukovic T, Stewart AJ, Cramb G. A role for inositol monophosphatase 1 (IMPA1) in salinity adaptation in the euryhaline eel (Anguilla anguilla). FASEB J. 2010;24(10):3981-91.

75. Kalujnaia S, Cramb G. Regulation of expression of the myo-inositol monophosphatase 1 gene in osmoregulatory tissues of the European eel Anguilla anguilla after seawater acclimation. Ann N Y Acad Sci. 2009;1163:433-6.

76. Gardell AM, Yang J, Sacchi R, Fangue NA, Hammock BD, Kultz D. Tilapia (Oreochromis mossambicus) brain cells respond to hyperosmotic challenge by inducing myo-inositol biosynthesis. J Exp Biol. 2013;216(Pt 24):4615-25.

77. Sacchi R, Li J, Villarreal F, Gardell AM, Kultz D. Salinity-induced regulation of the myo-inositol biosynthesis pathway in tilapia gill epithelium. J Exp Biol. 2013;216(Pt 24):4626-38

78. Tse WKF, Lai KP, Takei Y. Medaka osmotic stress transcription factor $1 b$ (Ostf1b/TSC22D3-2) triggers hyperosmotic responses of different ion transporters in medaka gill and human embryonic kidney cells via the JNK signalling pathway. International Journal of Biochemistry \& Cell Biology. 2011:43(12):1764-75

79. Tse WKF, Wong CKC. nbcel and $\mathrm{H}+-$ atpase mRNA expression are stimulated in the mitochondria-rich cells of freshwater-acclimating Japanese eels (Anguilla japonica). Can J Zool-Revue Canadienne De Zoologie. 2011;89(4):348-55 
80. Li JW, Lai KP, Ching AK, Chan TF. Transcriptome sequencing of Chinese and Caucasian population identifies ethnic-associated differential transcript abundance of heterogeneous nuclear ribonucleoprotein K (hnRNPK). Genomics. 2014;103(1):56-64.

81. Grabherr MG, Haas BJ, Yassour M, Levin JZ, Thompson DA, Amit I, et al. Full-length transcriptome assembly from RNA-Seq data without a reference genome. Nat Biotechnol. 2011;29(7):644-52.

82. Haas BJ, Papanicolaou A, Yassour M, Grabherr M, Blood PD, Bowden J, et al. De novo transcript sequence reconstruction from RNA-seq using the Trinity platform for reference generation and analysis. Nat Protoc. 2013;8(8):1494-512.

83. Ewen-Campen B, Shaner N, Panfilio KA, Suzuki Y, Roth S, Extavour CG. The maternal and early embryonic transcriptome of the milkweed bug Oncopeltus fasciatus. BMC Genomics. 2011;12:61.

84. Du H, Bao Z, Hou R, Wang S, Su H, Yan J, et al. Transcriptome sequencing and characterization for the sea cucumber Apostichopus japonicus (Selenka, 1867). PLOS ONE. 2012;7(3):e33311.

85. Rivera MC, Jain R, Moore JE, Lake JA. Genomic evidence for two functionally distinct gene classes. Proc Natl Acad Sci U S A. 1998;95(11):6239-44.

86. Li B, Dewey CN. RSEM: accurate transcript quantification from RNA-Seq data with or without a reference genome. BMC bioinformatics. 2011;12:323.

87. da Huang W, Sherman BT, Lempicki RA. Systematic and integrative analysis of large gene lists using DAVID bioinformatics resources. Nat Protoc. 2009:4(1):44-57.

88. Tse WKF, Chow SC, Wong CKC. The cloning of eel osmotic stress transcription factor and the regulation of its expression in primary gill cell culture. J Exp Biol. 2008:211(12):1964-8.

89. Pfaffl MW. A new mathematical model for relative quantification in real-time RT-PCR. Nucleic Acids Res. 2001;29(9):e45.

\section{Submit your next manuscript to BioMed Central and we will help you at every step:}

- We accept pre-submission inquiries

- Our selector tool helps you to find the most relevant journal

- We provide round the clock customer support

- Convenient online submission

- Thorough peer review

- Inclusion in PubMed and all major indexing services

- Maximum visibility for your research

Submit your manuscript at www.biomedcentral.com/submit 